\section{Expectations, Open Market Operations, and Changes in the Federal Funds Rate}

\author{
John B. Taylor
}

T he process through which Federal Reserve decisions about monetary policy are transmitted to the federal funds market has changed significantly in recent years. In 1994 the Federal Open Market Committee (FOMC) began to issue a public statement whenever it increased or decreased its target for the federal funds rate. This target is now the focus of activities at the Trading Desk at the Federal Reserve Bank of New York. In particular, the FOMC directs the Trading Desk to buy and sell securities so that conditions in the federal funds market are consistent with an average federal funds rate near this target. While FOMC decisions in earlier years were made in terms of a federal funds rate target, these decisions were communicated to the market in a less explicit way than they are now, and the communications were misinterpreted on a number of occasions. ${ }^{1}$ Now, when the FOMC publicly announces changes in its funds rate target, the market reacts very quickly and sometimes without any immediate open market purchases or sales by the Trading Desk to alter the supply of Fed balances. ${ }^{2}$ As stated by Meulendyke (1998, p. 142), "The rate has tended to move to the new, preferred level as soon as the banks knew the intended rate."

There have also been regulatory and technological changes affecting the federal funds market. Starting in July 1998 the Federal Reserve changed from a contemporaneous system of reserve accounting to a lagged system similar to a policy in place years ago. Under the new lagged reserve requirements, the two-week reserve maintenance period begins 17 days after the end of the two-week reserve

At the time he prepared this article, John B. Taylor was a professor of economics at Stanford University. He is currently the Under Secretary for International Affairs at the U.S. Department of the Treasury. The views expressed in this article do not necessarily represent the views of the Department of the Treasury. The author thanks Peter Fisher, Craig Furfine, Spence Hilton, Sandra Krieger, John Lipsky, Athanasios Orphanides, James Patterson, John Partlan, Dan Thornton, Glenn Rudebusch, Ken West, and Julian Wright for very helpful comments and discussions. computation period. This has probably led to better estimates of reserve requirements by the Trading Desk and the banks, but it has also eliminated the possibility of any contemporaneous response of required reserves to the interest rate.

Another significant change made possible by computer technology is the ability of financial institutions to efficiently "sweep" their consumers' accounts from those with reserve requirements into those without reserve requirements. These sweeps have allowed required reserve balances to decline sharply from about $\$ 30$ billion in 1990 , to $\$ 15$ billion in 1996, to only about $\$ 5$ to 6 billion today. As a result, holding Fed balances to facilitate interbank payments is of greater importance for many banks than holding reserves for legal requirements. At the same time, technology has improved the speed and accuracy with which banks can keep track of their payment inflows and outflows and thereby may have reduced the demand for Fed balances. ${ }^{3}$

In December 1999 the FOMC further expanded and clarified its public announcement policy. It began to issue a public statement after every meeting indicating not only its current decision about the federal funds rate target, but also which factor"the risks of heightened inflation pressures or economic weakness in the foreseeable future"is likely to affect upcoming decisions about the target. Although the statement about possible future actions is not part of the FOMC's directive to the Trading Desk, it could have indirect effects on the Desk's transactions if it affected the demand for Fed balances. See Federal Reserve Board (2000) for a summary of the announcement policies from 1994 to 2000.

The purpose of this paper is to develop a simple model of the federal funds market that reflects some of these changes and that can be used to investigate other changes. The model makes use of a "Trading Desk reaction function" to describe the changes in the supply of Fed balances over time. The model also makes use of important recent microeconomic research by Furfine $(1998,2000 a)$ and by Guthrie

\footnotetext{
1 Messages about federal funds rate target changes were sent through specific types of purchases or sales of securities under certain circumstances. Rudebusch (1995) shows that the market did not always get the message about the timing or the magnitude of the change.

2 Thornton (2000) refers to this phenomenon as "open mouth" operations, following the terminology of Guthrie and Wright (2000) who examined it in the case of the Reserve Bank of New Zealand.

3 This may be why neither excess reserves nor funds rate volatility has increased with the decline in required reserve balances.
} 
and Wright (2000) to explain the demand for Fed balances. ${ }^{4}$ Expectations are very important in the model because the Trading Desk is assumed to follow the reaction function day after day and because the demand for Fed balances depends in part on expectations of the future federal funds rate. I use the model to show how changes in the target for the federal funds rate can sometimes affect the actual funds rate even without any current open market operations. However, this effect requires credibility that the Trading Desk will follow a reaction function on future days. That way the Trading Desk is expected to do open market operations in the future if necessary. In effect, the expectation of future open market operations moves the federal funds rate today. I also examine whether the model can explain the serial correlation structure of the deviations of the actual rate from the target rate.

I begin with a description of the structure of the daily federal funds market-looking at the price discovery process and the timing of trading activity during the day. I then describe the time series behavior of the deviations of the actual federal funds rate from the target rate, placing special emphasis on the nine target rate changes from mid-1998 through 2000 and the unusually large deviations of the federal funds rate from the target rate at the end of 1999. It appears that the volatility of these deviations has been diminishing over this time period, with a big reduction in volatility around the time of the target rate changes. This may indicate that the federal funds market has been incorporating the target rate information into the price discovery process more quickly. I then describe the daily model of the federal funds market, briefly compare it with classic models of the supply and demand for reserves (e.g., Gilbert, 1985) and examine some representative simulations of the model.

\section{TRADING IN THE FEDERAL FUNDS MARKET}

A model of the federal funds market can only be a rough approximation of the complex trading that actually takes place in the federal funds market. To understand the nature of the approximation it is necessary to consider the actions and the incentives of the federal funds traders who buy and sell in the market each day. Federal funds traders are usually employed by financial institutions-frequently banks. Banks hold deposits at the Federal Reserve, which are referred to as Fed balances. ${ }^{5}$ The traders do most of the buying and selling of federal funds over the telephone, using modern telecommunications networks just like bond and foreign exchange traders. At large financial institutions federal funds traders might be on the same floor with the traders in other markets so they can easily get information about what is happening in government securities and other short-term markets.

\section{The Traders' Bids and Asks}

The federal funds market is essentially a "double auction" market in which buyers bid and sellers ask different prices on overnight loans of federal funds. ${ }^{6}$ Buying federal funds means borrowing Fed balances overnight. Selling federal funds means loaning Fed balances overnight. The price of federal funds is thus the overnight interest rate. Financial institutions hold Fed balances (again, deposits at the Fed) for two main reasons: (i) to satisfy reserve requirements and clearing balance requirements and (ii) to facilitate large payment flows. Some financial institutions have more Fed balances than they desire to hold on a given day; they will seek to sell (loan) the balances overnight to some other financial institution; their traders will try to get the highest price (overnight interest rate) that they can. Other financial institutions may find that they have fewer Fed balances than they desire; their traders will try to buy (borrow) Fed balances at the lowest price (interest rate) they can. When a buyer's bid is matched by a seller's ask, a trade takes place at the agreed upon interest rate. Buyers are rewarded for getting a low price on the market, and sellers are rewarded for getting a high price on the market.

At the start of the day federal funds traders usually have some expectation of whether their institution will be a net buyer or net seller that day. Large banks are frequently net buyers, though there are exceptions. A trader who anticipates having Fed

\footnotetext{
4 See Furfine (2000a) for references to earlier models of the federal funds market.

5 Note that Fed balances, which will be the quantity focused on in this paper, are quite a bit different from reserves. Fed balances do not include vault cash and do include required clearing balances. More specifically, Fed balances are equal to the sum of required balances plus excess reserves. Note that required balances include both required reserve balances and required clearing balances. Required reserve balances are the part of reserve requirements that are not satisfied with applied vault cash. Other terms sometimes used to describe Fed balances are "operating balances" or "aggregate supply of balances" or simply "balances."

6 There is also a small market in longer-maturity federal funds, but here I focus on the one-day (overnight) market
} 
balances to sell during the day may ask a high interest rate early in the day and then wait until the market starts to move before lowering the ask. That trader is hoping that another institution will suddenly be short of Fed balances and be willing to pay that price. A trader who anticipates having to buy funds may bid a low price and wait in the same way. Of course the unexpected can happen. A bank may get an unexpected payment outflow or inflow and suddenly change the strategy. Or a trader may hear a rumor and decide to enter the market early. Banks want to avoid being in an overnight overdraft position; the Fed charges a large penalty (400 basis points over the effective federal funds rate for that day) for overnight overdrafts.

The pace of federal funds trading varies a lot throughout the day, but it has a regular daily rhythm. The market is frequently very slow early in the day, and it is not unusual for the traders at even large financial institutions to have no trades for several hours in the morning; but trading frequently becomes quite chaotic toward the end of the day. Large financial institutions therefore need to have several traders available to handle large changes in volume.

\section{The Federal Funds Brokers}

A large portion of federal funds trades goes through federal funds brokers. ${ }^{7}$ The brokers are linked electronically to their clients - the federal funds traders - though they are generally at different physical locations. Of course, the main role of the brokers is to match up the buyers and the sellers, but the brokers also provide information to the buyers and sellers about trends they see in the market during the day. Brokers record (sometimes using white boards on the walls of the large rooms where they work) all the outstanding bids and asks from the traders who are their clients. Furfine (1998) estimates that there are about 1,000 participants in the federal funds market with about $\$ 144$ billion in trades each day (these numbers refer to 1998). Any one brokerage firm therefore needs to have many individuals handling the bids and asks of different clients.

At some times during the day the highest outstanding bid recorded on the white board is lower than the lowest outstanding ask recorded on the white board; at those times no trades take place (though if there is a small difference a broker may get on the phone and encourage either the buyer or seller to move a little bit). When a buyer calls in a bid that is equal to the existing ask of a seller (or vice versa), the broker notes the match, informs the buyer and the seller, and receives a commission for making the match. The buyer and the seller then arrange for the funds to be transferred from the selling institution to the buying institution, frequently through FedWire, the transfer system operated by the Federal Reserve for large value payments. (Some loans are made between small banks and their correspondents and are simply noted by bookkeeping entries). When trading volume increases-frequently toward the end of the day - there is no time to actually record all the bids and asks because they are changing so quickly; then there is only a record of the bilateral trades.

\section{The Trading Desk}

One thing the traders look for during the day is the size of the open market purchases or sales by the Trading Desk of the New York Fed. Temporary injections and temporary withdrawals of Fed balances through open market operations generally occur at one time during the day. Currently (since April 1999) the Trading Desk enters the market during a ten-minute interval around 9:30 a.m. with the exact minute determined randomly by rolling a die. The Trading Desk uses repurchase agreements (RPs) to increase Fed balances and matched salepurchase agreements (MSPs) or reverse RPs to reduce Fed balances. To be sure, neither the Trading Desk nor any other part of the Fed participates directly in the federal funds market. Rather, the Fed participates in the RP or the Treasury security market, increasing or decreasing the level of Fed balances, not the flow of federal funds transactions among banks.

Many of the temporary injections and withdrawals of Fed balances by the Trading Desk (via RPs and MSPs) are intended to offset predicted short-run changes in the supply of Fed balances (due, for example, to changes in currency or U.S. Treasury balances) or in the demand for Fed balances. But some injections or withdrawals are aimed at moving the supply of Fed balances in order to increase or decrease pressure on the federal funds rate and thereby bring the federal funds rate closer to the target. It is very difficult to distinguish empirically between (i) Trading Desk purchases and sales that are designed to decrease or increase pressure

\footnotetext{
7 Furfine (1998) provides a very rough estimate that about four-fifths of funds trades go through brokers; this is based on an extrapolation (using FedWire transactions growth) from the late 1980s when the total daily volume of brokered trades in the federal funds market was estimated to be about $\$ 70$ billion.
} 
on the federal funds market (to guide the interest rate toward its target) and (ii) open market operations designed to offset factors that shift the supply or demand for Fed balances. The latter appear to be much greater in volume than the former especially if permanent increases are included. Over longer periods of time, by far the greatest reason for permanent injections of Fed balances is to offset increases in currency. 8

The flow of trades in the federal funds market (about $\$ 150$ billion per day) is more than ten times greater than the stock of Fed balances. This big stock-flow difference is true for many individual banks; for example, a bank might hold less than $\$ 100$ million in balances at the Fed and buy (borrow) $\$ 4$ billion in the federal funds market on a typical day. Such a bank buys funds in the federal funds market to make loans in other markets; the banks that sell federal funds to the large bank must have more deposits than the sum of their loan opportunities and Fed balance needs. That federal funds purchases are a source of funds for other loans creates a connection between the federal funds rate and the other loan rates.

\section{The Daily Effective Federal Funds Rate}

It is clear from the above discussion that each bilateral trade in the federal funds market can take place at a different price. In fact, Furfine (1999), using data on individual federal funds trades collected from FedWire records, has documented that there are significant price differences, even at the same time during the day. Some of these price differences are correlated with the size of the banks, the volume of their trading, and the size of the transaction - factors that may be related to risks or transaction costs. But there are also differences within the day for the same banks. The commonly reported daily effective federal funds rate is a weighted average of the rates on trades reported by brokers. It is this daily effective rate that the Trading Desk is instructed by the FOMC to keep on average around the target rate.

The time series analysis and the model in this paper focus on the behavior of this effective rate. The effective rate incorporates a lot of cross section and interday volatility. For example, on December 30, 1999 , there was more than a 100 basis point difference between the rate on early morning trades and the daily effective rate (Fisher, 2000, Chart 30). Some single trades at the end of the day can be several percentage points away from the effective rate on that day when a bank finds itself to have a shortage or surplus of funds at the last minute. In fact, there is much more price information in the market than the effective rate itself. An important task for future research is to use microeconomic data of the kind Furfine (1999) has assembled to study price formation and price dynamics in the federal funds market in more detail.

\section{THE RECENT TIME SERIES PROPERTIES OF THE DAILY EFFECTIVE FEDERAL FUNDS RATE}

Figure 1 shows the daily effective federal funds rate along with the target rate for the period from July 1998 to September 2000. I focus on this period because it is after the big changes mentioned in the opening paragraphs of the paper, including the public announcements of changes in the target rate and lagged reserve accounting. It also incorporates a relatively large number of changes in the target rate-three down and six up. In contrast there were only two target rate changes in the two years before this-one in 1996 and one in 1997. With daily data there are 550 observations on the effective federal funds rate during this period. Weekends are excluded because the federal funds market is not open on weekends. (Holidays not falling on a Saturday or Sunday were not excluded so as to keep a repeating 10-day interval - the maintenance periodduring the sample.)

\section{Volatility}

It is clear from Figure 1 that the Trading Desk has been very successful in following the FOMC's directive to keep the daily effective federal funds rate at an average around the target. Figure 2 shows the deviations in percentage points between the effective rate and the target. The average deviation for this period was 0.1 basis points, so there is clearly no bias between the target and the actual rate that persists over time. The maximum deviation was -150 basis points and occurred on December 31 , 1999 , the day of the century date change. The standard deviation of the actual rate-target rate deviation over this period was 18 basis points.

Note that the volatility of the federal funds rate has been declining during this period; the standard

\footnotetext{
8 More lasting changes in the factors affecting the supply of Fed balances are offset by outright purchases of Treasury securities; these can occur at any time during the day. In 1999 the total System open market portfolio increased by $\$ 44$ billion.
} 


\section{Figure 1}

\section{Federal Funds Rate and Target Rate}

July 1998-September 2000

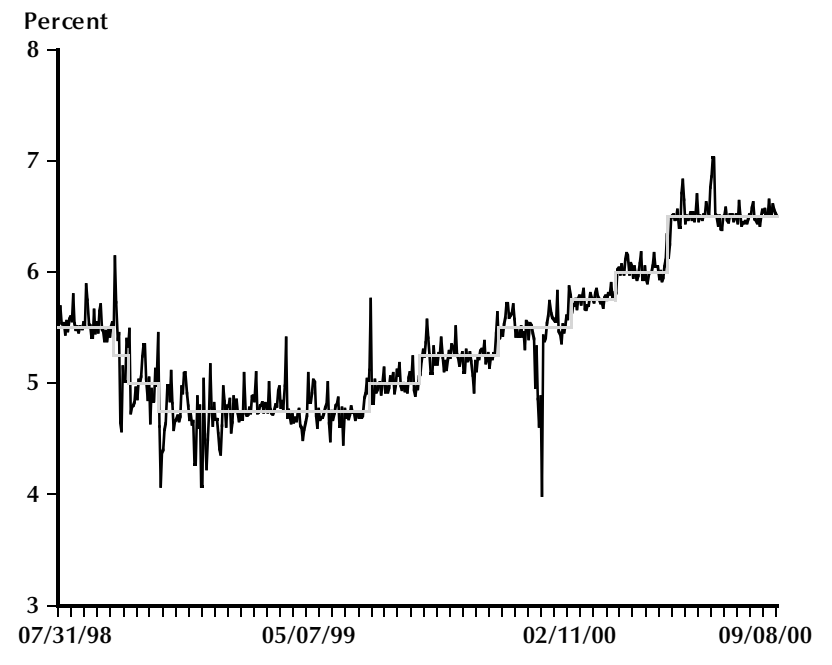

deviation was 20 basis points from August 1998 to July 1999 and 16 basis points since July 1999 (even including the large deviations at the end of 1999). During this two-year period sweep accounts continued to lead to lower levels of required reserve balances, which some had thought would increase volatility; the decline in volatility indicates either that the lower level of required reserves has not made reserve management more difficult for banks or that there have been countervailing forces. One such force has been greater certainty about the federal funds target; other possibilities are better information about payment flows, perhaps made possible with lagged reserve requirements.

\section{Serial Correlation and Persistence}

The deviations of the federal funds rate from the FOMC's target rate are not serially independent, but they show rapid mean reversion for daily data. Let $d_{t}$ be the deviation of the daily federal funds rate from the target federal funds rate; that is, $d_{t}=\left(r_{t}-\rho_{t}\right)$ where $r_{t}$ is the daily effective federal funds rate and $\rho_{t}$ is the target rate. Equation (1) below is a first-order autoregression in the deviation $\left(d_{t}\right)$ estimated over the period from August 3 , 1998, to September 8, 2000.

(1)

$$
d_{t}=\underset{(0.038)}{0.4221 d_{t-1}+0.0008+e_{t}} \quad \sigma_{e}=0.166, \quad R^{2}=0.18
$$

\section{Figure 2}

\section{Deviations of the Federal Funds Rate from Target}

July 1998-September 2000

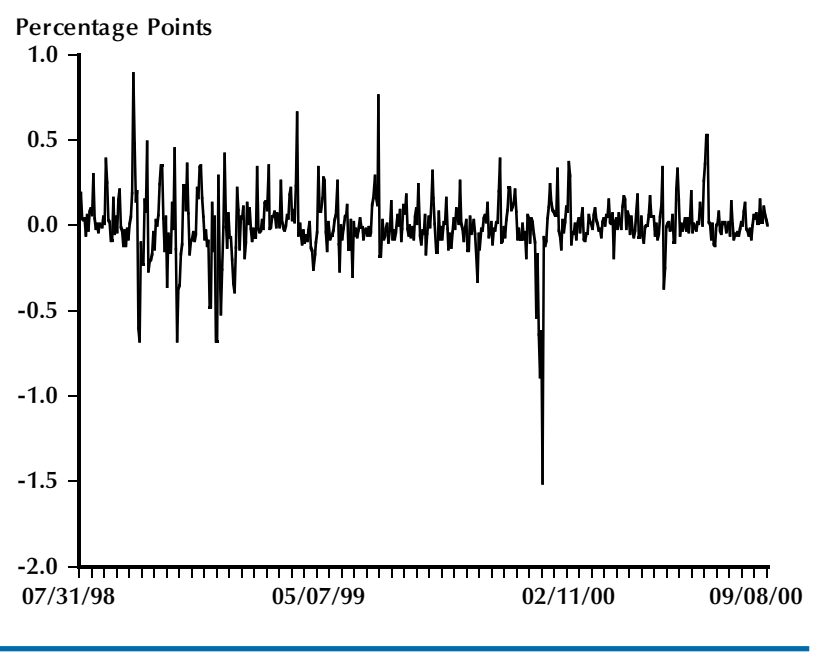

The coefficient on the lagged dependent variable has a very low estimated standard error and is very significantly different from zero and one. ${ }^{9}$ On average only about 6 percent of a deviation persists beyond two days.

Serial correlation of the deviations has increased during the past two years, as measured by the coefficient on the lagged dependent variable. For the days from August 1998 to July 1999, the coefficient on the lagged dependent variable was 0.3690; from August 1999 to September 2000 it was 0.4932. This increase in persistence parallels the reduced volatility and could reflect greater smoothing of shocks, either through the actions of market participants or by the Trading Desk.

\section{Settlement Wednesday and Other Maintenance Period Effects}

During this period there was only a small difference between the average funds rate on the last day of the maintenance period-settlement Wednesday - and other days. The settlement Wednesday average of the funds rate deviation $\left(d_{t}\right)$ was 6 basis points below the average of zero for the whole period. This is in contrast to the finding of Hamilton (1996) in which the funds rate traded an

9 The simple first-order assumption seems sufficient to capture the time series behavior during this period. See Rudebusch (1995) for estimates during earlier periods and for a discussion of outlier issues. 
Figure 3

\section{Federal Funds Rate at Century End}

(quotes from Fisher, 2000)

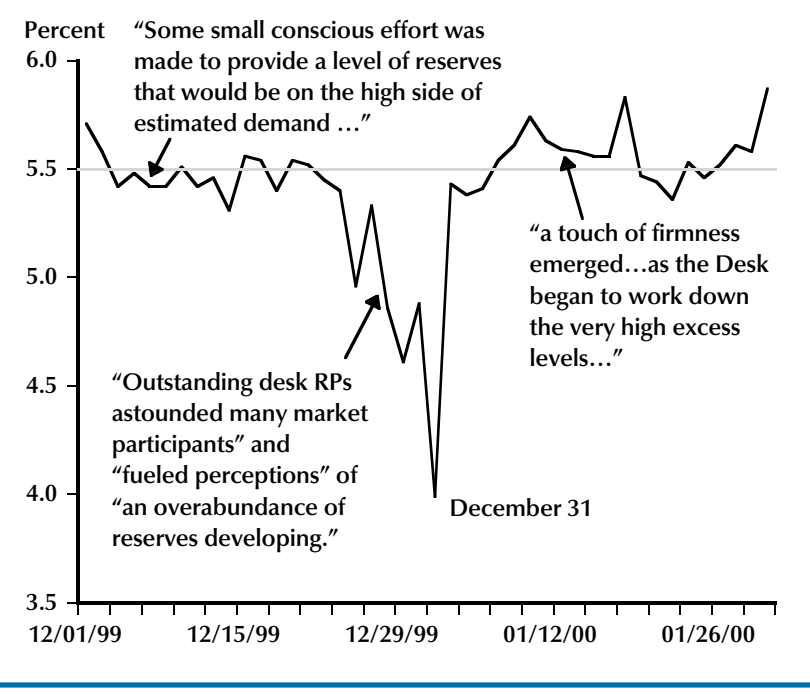

average of 14 basis points above average on settlement Wednesdays in earlier years. The report by Fisher (2000) also notes this change, with the settlement Wednesday deviations being positive in 1996 and 1997 and negative in 1998 and 1999. The average negative deviations seem to be persisting into the year 2000. The tendency of federal funds to trade relatively low on Fridays and relatively high on Mondays is continuing. ${ }^{10}$

\section{The Century Date Change Deviation}

It is instructive to examine what happens during unusually large and persistent deviations of the daily effective rate and the target rate. The largest and most persistent deviation during the last several years was the one that occurred at the end of 1999. Figure 3 shows this deviation on December 31 , 1999 , as well as on the days before and after; Figure 3 also superimposes some relevant passages from the annual report from the System Open Market Account (Fisher, 2000) that explains what the Trading Desk was doing during this period.

Clearly the deviation was related to the century date change and to the activities of the Trading Desk to make sure that there was adequate liquidity during this period. For example, during the whole month of December the Trading Desk was putting a little more reserves into the market than it otherwise would have done; this led to a federal funds rate slightly below the 5 percent target rate for much of December, but still within the 20 basis point standard deviation of the whole sample period. However, the rate fell sharply in the days after the Christmas holiday and especially on New Year's Eve. During the last days of the year the Trading Desk was doing a large amount of temporary open market purchases (through RPs) to offset unusually large drains on Fed balances due to both increased demands for currency (by the public and by the banks) as well as increases in U.S. Treasury balances. The large amount of RPs by the Trading Desk was noted by federal funds traders; many thought it would create a surplus of Fed balances in the market. Apparently they did not know that the drain on reserves was as strong as it was. This perception of "an overabundance of reserves" led to funds rate trades at prices well below the FOMC's target; the daily effective rate fell below 4 percent.

The situation quickly reversed when trading began in January 2000. In fact, the effective rate traded above the target for most of January. According to the annual report in Fisher (2000), this pressure in the market occurred as the Trading Desk was rapidly offsetting the effects of declines in currency demand. Evidently it was this increased pressure on the reserve market that caused the federal funds rate to trade high for all of January.

\section{Target Rate Changes}

How has the federal funds rate moved at times of changes in the target rate during the 1998-2000 period? Figure 4 shows the changes of the federal funds rate for the nine changes in the target rate during this period. The exact dates of the target rate change are shown in Table 1. The actual federal funds rate moves very quickly around the times of the changes in the target rate.

Table 2 shows that there has been a sharp reduction in the volatility of the funds rate around the times of the target rate changes. The standard deviation of the difference between the funds rate and the target rate was about 28 basis points for the first four target range changes in Figure 4 and only 12 basis points for the latter five. In three of the latter five cases the funds rate appeared to move significantly before the change in the target, indicating

\footnotetext{
${ }^{10}$ Dan Thornton has pointed out to me that, because the distribution of funds rates on settlement Wednesday is skewed to the right, negative deviations have usually been more common than positive deviations, even though the average deviation (over the period from 1974 to 1997) has been positive.
} 


\section{Figure 4}

Nine Changes in the Target for the Federal Funds Rate: 1998-2000
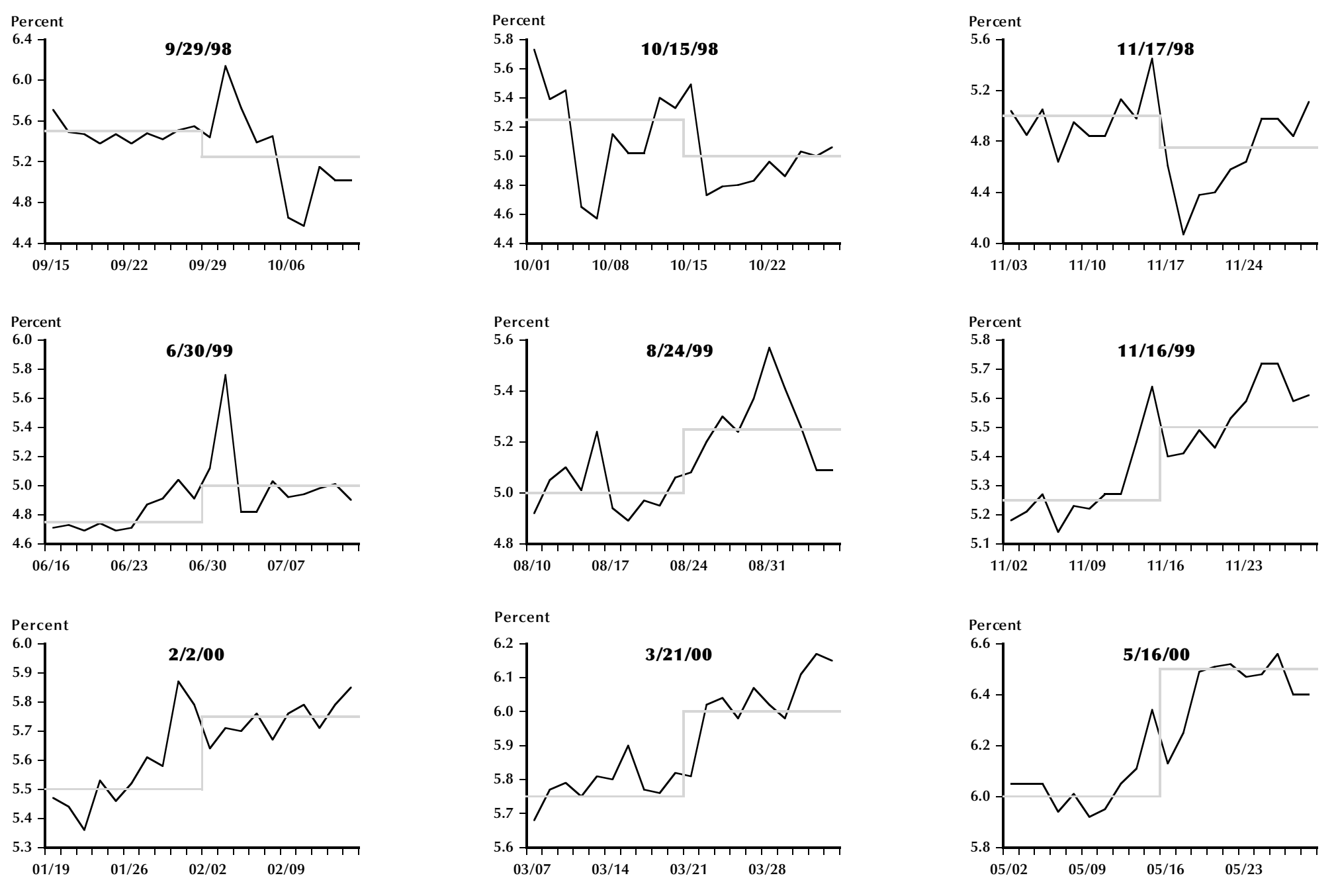


\section{Table 1}

Changes in Target Federal Funds Rate: 1998-2000

\begin{tabular}{|c|c|c|c|c|}
\hline Date & Day of week & $\begin{array}{c}\text { Day of } \\
\text { maintenance period }\end{array}$ & $\begin{array}{c}\text { New target } \\
\text { for funds rate }\end{array}$ & $\begin{array}{l}\text { Change in } \\
\text { target rate }\end{array}$ \\
\hline September 29, 1999 & Tuesday & 4 & $51 / 4$ & $-1 / 4$ \\
\hline October 15, 1998 & Thursday & 6 & 5 & $-1 / 4$ \\
\hline November 17, 1998 & Tuesday & 9 & $43 / 4$ & $-1 / 4$ \\
\hline June 30, 1999 & Wednesday & 10 & 5 & $+1 / 4$ \\
\hline August 24, 1999 & Tuesday & 9 & $51 / 4$ & $+1 / 4$ \\
\hline November 16, 1999 & Tuesday & 9 & $51 / 2$ & $+1 / 4$ \\
\hline February 2, 2000 & Wednesday & 4 & $53 / 4$ & $+1 / 4$ \\
\hline March 21, 2000 & Tuesday & 9 & 6 & $+1 / 4$ \\
\hline May 16, 2000 & Tuesday & 9 & $61 / 2$ & $+1 / 2$ \\
\hline
\end{tabular}

\section{Table 2}

\section{Behavior of Federal Funds Rate (FFR) Near Target Federal Funds Rate (TFFR) Changes}

\begin{tabular}{lccc} 
Date & $\begin{array}{c}\text { Not Granger-causing } \\
\text { F-test, probability value } \\
\text { TFFR not } \rightarrow \text { FFR }\end{array}$ & FFR not $\rightarrow$ TFFR & $\begin{array}{c}\text { Volatility: standard } \\
\text { deviation (basis points) } \\
\text { during 20 day interval }\end{array}$ \\
\hline September 29, 1998 & .0005 & .4360 & 34 \\
October 15, 1998 & .0881 & .9434 & 29 \\
November 17, 1998 & .0123 & .1560 & 27 \\
June 30, 1999 & .0001 & .4077 & 21 \\
August 24, 1999 & .0090 & .7587 & 13 \\
November 16, 1999 & .0142 & .0107 & 13 \\
February 2, 2000 & .2442 & .0171 & 12 \\
March 21, 2000 & .0090 & .7587 & 8 \\
May 16, 2000 & .0142 & .0108 & 1
\end{tabular}

perhaps that the target change itself was anticipated. Table 2 provides some rough statistical support for this visual impression about the timing. It reports the probability value of a test of the hypothesis that (i) the target rate does not Granger-cause the federal funds rate and that (ii) the federal funds rate does not Granger-cause the target rate. The first hypothesis is rejected uniformly, but the second is rejected only in the three cases mentioned above.

\section{A Model of the Supply of Fed Balances}

The Trading Desk determines the supply of Fed balances and tries to keep an appropriate supply relative to demand with the federal funds target in mind. Most of the transactions of the Trading Desk aim to neutralize other factors that shift the supply or the demand around. Each day the staff at the New York Fed and the Board compare notes on the factors that are affecting the supply of and the demand for Fed balances. As mentioned above, changes in currency in circulation and changes in Treasury balances are two of the factors that must be offset. The Fed does a good job at estimating and thus neutralizing these flows. A good case study is how the remarkable increase in currency and in U.S. Treasury cash balances in December 1999 was offset. These increases, along with a similarly motivated increase in demand for cash by foreign central banks, led to a huge drain on Fed balances: \$70 billion in only two weeks from mid-December until 
the end of the year. The Desk neutralized this drain by doing about the same amount of RPs. This $\$ 70$ billion of purchases is many times greater than the total amount of Fed balances, so efforts to alter the pressure on Fed balances would have to involve a much smaller amount of purchases and thus would be very hard to observe simply by looking at open market transactions. Moreover, pressure up or down can be exerted by doing slightly fewer or more RPs (or MSPs) than would otherwise be required to offset the other factors. For example, an increase in Fed balances of 2 percent would be only about $\$ 200$ million - that is, only a fraction of a percent of the offsetting purchases during this period.

\section{A Trading Desk Reaction Function}

In any case, the directive to the Trading Desk is to foster conditions in the federal funds market that will keep the federal funds rate close to the target. That means that the Trading Desk must adjust the supply of Fed balances up and down to keep the federal funds rate close to the target even as it is making much larger offsets to other factors that shift the supply and demand for Fed balances. If the Trading Desk follows such a procedure systematically, then one should be able to model the procedure with some kind of a reaction function. One possibility, which seems to capture the words of the directive and the way market participants think about the Desk's actions, is the reaction function shown in equation (2):

$$
b_{t}=b_{t-1}+\beta\left(r_{t-1}-\rho_{t-1}\right) \text {, }
$$

where $b_{t}$ is the supply of Fed balances on day $t, r_{t}$ is the daily effective federal funds rate on day $t$, and $\rho_{t}$ is the target federal funds rate. It is important to recognize that equation (2) is designed to focus on Trading Desk activities over and above those that are taken to offset predicted shifts in supply and demand. For example, an increase in currency will require an open market purchase simply to keep $b_{t}$ from declining. That kind of Trading Desk action is implicit in equation (2). To make such actions explicit one would have to add shift terms to equation (2) and then have the Trading Desk offset those terms; but that would only clutter the notation with no gain in realism. Similarly, as mentioned above, some trading desk activity is designed to offset shifts in the demand for Fed balances, perhaps due to predicted seasonal factors or to known regulatory changes. According to the notation here, the symbol $b_{t}$ is assumed to be adjusted for these seasonal and other predicted changes in demand, in the same way that a seasonally adjusted series for the money supply adjusts for holiday demand for money. ${ }^{11}$

Now let me discuss the form of the reaction function in equation (1) and its rationale. The parameter $\beta$ is assumed to be positive. The time subscript on the target rate emphasizes that this rate does change, but of course it changes much less frequently than the daily effective rate. The target rate is determined by the FOMC's assessment of developments in the broader economy-such as inflation or real GDP - which usually change over a period of weeks or months rather than days. In this paper I will consider one-time changes in the target rate and see how the daily rate moves in response. I will assume that the Trading Desk follows this reaction function or policy rule in the analysis that follows. Since this analysis assumes that traders are forward looking, it is important to also stress that we assume that traders know that the Trading Desk follows such a reaction function and that they expect the Trading Desk to continue to follow it in the future. That equation (2) is expected to be followed in future periods has a big impact on how equation (2) actually affects the federal funds rate.

The reaction function in equation (2) captures several features of the Trading Desk's policy. First, according to equation (2) the FOMC increases the supply of reserves if the daily rate is above the target rate; presumably this increase in supply will reduce pressures on the federal funds market and tend to bring the actual rate back down to the target rate. Similarly, the Desk decreases the supply of reserves if the daily rate is below the target rate; the decreased supply then puts upward pressure on the federal funds rate. The coefficient of 1 on the lagged level of Fed balances implies that it is only the change in reserves that responds to the deviation between the actual rate and the target rate. The Desk therefore does not try to achieve a level of reserves (even in the long run), but simply changes reserves to bring the daily rate into line with the target rate. It is possible that the coefficient on the lagged reserve balances is less than 1 , but that would imply a unique level of reserves corresponding to the gap between the daily rate and the target rate.

\footnotetext{
11 By abstracting from the actions taken to offset known or predicted changes in supply and demand, I do not mean to imply that they are not important or interesting in their own right under current policy in the United States. On the contrary, as mentioned in the discussion above, such actions represent a major fraction of the actions of the Trading Desk's time and analysis.
} 
Another important feature of equation (2) is that the Trading Desk is assumed to make these adjustments in Fed balances with a lag; that is, $\left(r_{t-1}-\rho_{t-1}\right)$ appears in equation (2) rather than $\left(r_{t}-\rho_{t}\right)$. As discussed above, the Desk intervenes in the market in the morning, before most of the day's trading takes place and before the effective daily rate is even calculated. The first time the Desk can intervene under its current procedures is therefore the next day. Even if the Desk wanted to react on the same day, the timing of trading in the federal funds market described above - in particular with so much trading and price movements late in the day-would make it difficult to do so. To be sure, the lag could be longer or distributed over time, but equation (2) seems to capture an important feature of the necessarily lagged response in a simple way.

Equation (2) could be made more complex. The reaction could be nonlinear or the parameters could vary over time, or at least within days of the maintenance period. Another possibility would be to react to other variables, perhaps some other market interest rate, the maximum price in the federal funds market during the day, or the price of the last few trades, along with the effective rate. ${ }^{12}$ Such additions could provide a better description of actual behavior or work better from a normative perspective. But equation (2) without these modifications seems like a good place to begin.

\section{Comparison with the Classic Supply Curve for Reserves}

Equation (2) implies that the supply of Fed balances is a vertical line in a diagram with the current federal funds rate on the vertical axis and Fed balances on the horizontal axis. The vertical line moves back and forth over time as the daily funds rate fluctuates.

How does equation (2) differ from earlier graphical models of Trading Desk operations, such as the traditional supply and demand model by Gilbert (1985)? ${ }^{13}$ One difference is the explicit description of the dynamics; rather than simply considering a one-time shift in the supply of balances, equation (2) is a contingency plan for many such shifts. Another difference is that the supply of Fed balances in equation (2) is vertical throughout its whole range. In Gilbert (1985), the supply of Fed balances becomes sensitive to the contemporaneous federal funds rate when that rate goes above the discount rate. Thus the supply curve has a positive slope over part of its range. The higher the rate the more incentive banks have to borrow from the discount window; since more borrowing from the Fed increases the supply of Fed balances, this creates a positively sloped section of the supply curve. Given the reluctance of banks to borrow from the discount window and the apparent low interest rate elasticity of borrowing, it is a good approximation to assume that the supply curve is vertical throughout the range. ${ }^{14}$

Although many textbook uses of the classic supply of reserves model are vague about the time periods, Gilbert (1985) was careful to point out that the model applied to the (then one-week) maintenance period rather than to individual days. Also, "reserves" in the classic model (Gilbert, 1985) includes vault cash; in equation (2) the quantity variable refers only to the balances that financial institutions hold at the Fed. These balances include required reserve balances, required settlement balances, and excess reserves. There is a big difference between these measures. For example, in November 1999, required reserves were about $\$ 40$ billion of which about $\$ 34$ billion was applied vault cash, making required reserve balances about $\$ 6$ billion. Required clearing balances were about another $\$ 6$ billion, and excess reserves were about $\$ 1$ billion. Thus, Fed balances were about $\$ 13$ billion.

\section{A MODEL OF THE DEMAND FOR FED BALANCES}

Recent microeconomic research on the demand for Fed balances by financial institutions has emphasized the intertemporal nature of the decision to buy and sell Fed balances in the federal funds market. For example, Hamilton (1996) stressed that banks face an average reserve requirement over the 10 days of the reserve maintenance period (Fridays count three times as much in the average because the market is closed on weekends). This averaging

\footnotetext{
12 Modern research on policy rules has emphasized that it may be optimal to react to variables that are not in the objective function. For example, it is optimal for the FOMC to react to real variables when adjusting the federal funds rate target, even if real variables are not in the objective function.

${ }^{13}$ Woodford (2000) uses such a model to discuss interest rate setting by the Fed. Demand side differences between the model in this paper and the traditional model are discussed below.

14 Recent evidence of this well-known reluctance is provided by Furfine (2000b), who argues further that low utilization of the special borrowing facilities around the time of the century date change indicated that banks are very reluctant to borrow from the Fed even when they are encouraged to do so.
} 
would seem to allow federal funds traders to eliminate, through arbitrage, any predictable increases or decreases within each reserve maintenance period. For example, if a bank expects the federal funds rate to rise tomorrow, the bank should be willing buy Fed balances today and sell Fed balances tomorrow to take advantage of the differential; but such action, if taken by enough banks, will tend to eliminate the difference between today's rate and tomorrow's expected rate. Thus, the federal funds rate should not have any predictable movements, at least during the maintenance period. The reason that the rate does have predictable movements, according to Hamilton's (1996) model, is that transactions costs and limits on borrowing prevent full arbitrage. His model shows, for example, why the federal funds rate was regularly 14 basis points on average higher (during the period he studied) on settlement Wednesdays than on other days.

Furfine (2000a) presents a model that lays out the full intertemporal profit maximization problem for the typical bank in the federal funds market. His time horizon is many maintenance periods. He derives a first-order condition in which today's federal funds rate depends on expectations of the next day's federal funds rate. However, there are predictable movements in the rate because of the great reluctance of banks to be left with an overnight overdraft, as discussed above.

Furfine's (2000a) model also incorporates payment flows as a motivation for holding Fed balances, even for banks without binding required reserve balance or required clearing balance constraints. An examination of FedWire transactions shows that banks make about $\$ 2$ trillion in large-value payments each day, which is many times their stock of Fed balances. These FedWire payments create instantaneous debits or credits to a bank's Fed balances, and the payments can exceed Fed balances by a factor of several hundred. A bank's demand for federal funds is affected by this payments activity. Banks can have daylight overdrafts at relatively low cost; but, to avoid overnight overdrafts, banks buy Fed balances in the funds market whenever payment outflows would bring their accounts into overnight overdraft.

Guthrie and Wright (2000) also derive the demand for balances at the central bank from a detailed optimization problem. Their analysis is designed to describe operations of the New Zealand money markets where the Bank of New Zealand provides both a lending and a borrowing facility with a spread between the lending and borrowing rates. (The Bank of Canada recently adopted a similar method for controlling the overnight interest rate.) The demand for balances in the Guthrie-Wright analysis is thus based on the opportunity cost of borrowing from or lending to the Reserve Bank rather than to the market.

An important feature of Furfine's intertemporal model is that the expectation of the next day's federal funds rate affects the demand for Fed balances today. The effect does not have to be full arbitrage, where today's funds rate moves one-toone with expectations of tomorrow's rate or where arbitrage completely eliminates the difference between the expectation of tomorrow's rate and today's rate. A simple equation that reflects this effect on the demand for Fed balances is:

$$
b_{t}=-\alpha\left(r_{t}-\gamma E_{t} r_{t+1}\right)+\varepsilon_{t},
$$

where $\varepsilon_{t}$ is a demand shock (which might be serially correlated) and $E_{t}$ is the conditional expectation operator based on information through day $t$. The parameters $\alpha$ and $\gamma$ are constant with $\alpha>0$ and $1 \geq \gamma \geq 0$. As defined above, $b_{t}$ is the stock of Fed balances and $r_{t}$ is the daily effective federal funds rate.

Equation (3) incorporates the impact of the expectation of the next day's interest rate using the rational expectations assumption. Traders are assumed to forecast the next day's rate using the information available during the current day, including the Trading Desk reaction function and the demand for Fed balances. But equation (3) falls short of a full arbitrage assumption in two ways.

First, the expectation of the next day's rate is multiplied by a parameter $\gamma$ that may be less than 1 . Thus there may be a down-weighting of the next day's rate. Furfine (2000) allowed for such a downweighting in estimating his model and found that the value was less than 1 , but not significantly so.

Second, even if $\gamma$ were equal to 1 , equation (3) has a finite response of the stock of Fed balances to the difference between the current funds rate and the next day's funds rate. Only if $\alpha$ were infinite would $r_{t}$ have to equal $\gamma E_{t} r_{t+1}$ (or $E_{t} r_{t+1}$ if $\gamma$ was 1). In fact, transactions costs and high penalties for overnight overdrafts suggest that $\alpha$ should be less than infinity and possibly quite small.

As with the supply of Fed balances (equation (2)), the assumption about the demand for Fed balances (equation (3)) is an approximation. The size of both $\alpha$ and $\gamma$ is likely to vary across days in the maintenance period. Fridays count higher in the 
Figure 5

\section{Simulated Impact on the Daily Effective Federal Funds Rate of an Increase in the Target Funds Rate of 0.5 Percentage Points on Day 1}

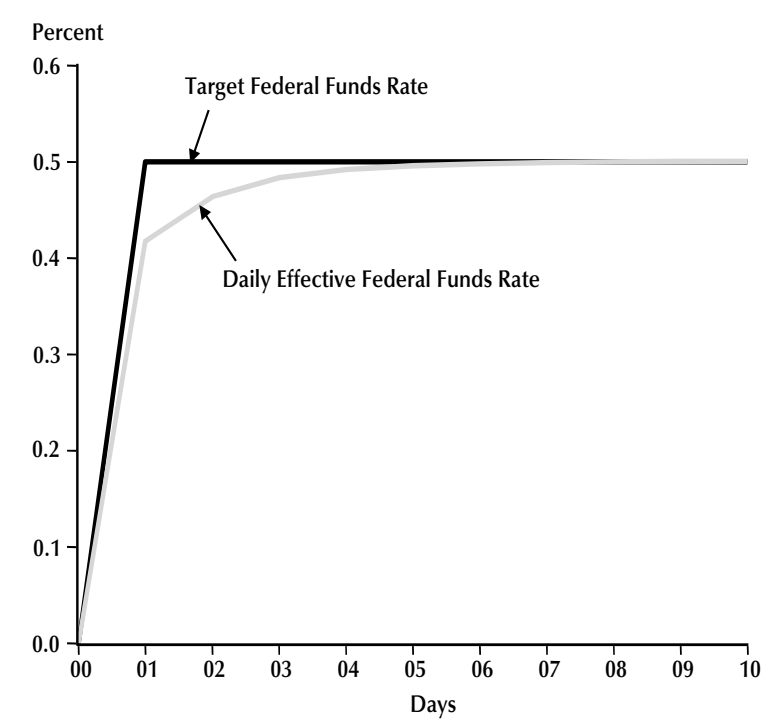

average, and on settlement Wednesdays the relevance of the next day's rate is less because the arbitrage connection between maintenance periods is limited by restrictions on carry-over provisions.

In fact, in discussing this paper with others I have found that there is a great deal of difference of opinion among economists and traders about the size of $\gamma$ and the theory that underlies this intertemporal effect. Most agree that $\gamma$ is greater than zero, which is the important property needed for the anticipatory movements in the funds rate as shown below. But it would be very useful to obtain estimates of $\gamma$ using daily Fed balance data and measures of all the factors that cause equation (2) to shift.

How does this demand equation differ from that of the demand equation in Gilbert (1985)? An important difference is that the interest rate elasticity of the demand for Fed balances is not derived from the interest rate elasticity of money demand through reserve requirements. Even when legal reserve requirements are binding, the fact that they are lagged means that there is a zero interest rate elasticity of required reserves. Another difference is that the expectation of the next period's interest rate enters the demand equation. It is this difference that makes the model interesting (in my view) and enables it to explain a number of the features in the data described above.

\section{CHANGES IN THE DAILY EFFECTIVE RATE IN RESPONSE TO SHOCKS}

Equations (2) and (3) together are a complete dynamic stochastic rational expectations model of the deviations of the daily effective federal funds rate from the target federal funds rate. Using these equations we can evaluate the ability of the model to explain some of the empirical regularities in the data, including the phenomenon that the federal funds rate changes immediately after a target change before any open market operations by the FOMC designed to move the rate. An advantage of the simple linear model is that it is very easy to solve.

\section{Simulations of a Change in the Target Federal Funds Rate}

Suppose that the FOMC votes to increase the federal funds target by 50 basis points. What does the model predict about the impact on the daily effective federal funds rate on the day of the announcement? Recall that the Trading Desk would not conduct an open market operation designed to change the supply of Fed balances on the day of the FOMC press release. Similarly, the Trading Desk reaction function in equation (2) would imply no change in the supply of Fed balances. Any such response will be lagged by one day, as is clear from equation (2). However, since the Trading Desk is assumed to follow equation (2) day after day, we know that, unless the funds rate immediately jumps by 50 basis points to the new target, the Trading Desk is expected by federal funds traders to decrease Fed balances on the next day. That is, $E_{t} b_{t+1}$ falls as the target rate goes above the daily rate on day $t$.

However, this expectation will cause the funds rate to rise on the day of announcement. Here is the intuitive reasoning: If Fed balances are expected to fall on day $t+1$, then the expectation of the federal funds rate on day $t+1$ must rise according to the demand equation (3); that is, $E_{t} r_{t+1}$ rises. But if the federal funds rate is expected to rise on day $t+1$, then the federal funds rate will rise today because demand shifts out today with the expectation of the future funds rate in the demand function.

We can simulate equations (2) and (3) to see the size and the patterns of the change in the federal funds rate. Figure 5 shows the results for a particular set of parameter values. In particular, I assume that $\gamma=0.9, \alpha=0.3$, and $\beta=0.1$. 
The federal funds rate increases by 41.7 basis points on the day of the 50 basis point announcement, even though there is no open market operation on that day designed to bring about this change. It is the expectation of a change in the next period that brings about this change. Note that most of the funds rate increase takes place immediately for these parameter values. On the next day the federal funds rate moves up by 4.7 more basis points for a cumulative increase of 46.4 basis points; on day 2 it increases further to 48.3 and continues to converge geometrically to the total 50 basis point change in the target.

Note that the increase in the funds rate from day 1 to day 2 is consistent with the Fed balance demand equation and with the supply of Fed balances not increasing at all on day 1 : With $r_{1}$ up by 0.417 and $r_{2}$ up by 0.464 , we have that $r_{1}-0.9 E_{1} r_{2}=$ $0.417-0.9(0.464)=0$, which is consistent with $b_{1}$ remaining at zero. However, from day 2 to day 3 the increase in the daily rate increases by a smaller proportion so that $r_{2}-0.9 E_{2} r_{3}=46.4-0.9(48.3)>0$; this reduces the quantity of Fed balances demanded. This reduction is consistent with the fact that the Trading Desk must, if it follows its rule, reduce the supply of Fed balances on day 2.

In sum we have shown that the model can explain why the daily effective funds rate might move on the day of announcement of the target change even though there has been no change in balances. There is the appearance of what Guthrie and Wright (2000) refer to as an open mouth operation: the announcement of the target rate change brings about an actual rate change of almost the same magnitude without any immediate change in Fed balances. However, as the model shows, if expectations are rational the Trading Desk must actually respond to any realized differences between the funds rate and the target rate; in other words, its actual policy must be consistent with the announced policy. Otherwise, funds traders will soon begin to expect that there is some other policy reaction function at work and expectations will form in a different manner.

To be sure, while the movements of the federal funds rate at the times of the federal funds rate target changes (shown in Figure 4) seem to be getting closer to the movements in the targets, the timing is not as precise as the model. There are big differences in the exact time that the funds rate changes: Sometimes the rate changes before the day of the announcement and other times with more of a delay.
Moreover, the model may be too successful. There is evidence from federal funds futures markets that changes in the federal funds rate target are sometimes anticipated by the market many days or even many weeks before they actually take. ${ }^{15}$ In such cases the model in equations (2) and (3) suggests that the actual federal funds rate should move somewhat with these anticipations, yet such movements are hard to detect. One explanation consistent with the model is that the Trading Desk offsets the pressure for the current rate to change, but further research is needed to determine whether these effects can be modeled accurately.

\section{Simulation of the Effect of a Shock to Fed Balances}

How rapidly does the federal funds rate return to the target funds rate after a shock to the demand for Fed balances? Figure 6 shows the simulated response to a permanent shock to equation (3) on day 1 . The daily rate immediately increases on day 1 , but the Trading Desk does not respond immediately. The rate begins to move back to target on day 2 , and within three or four days the shock's effect has largely disappeared. The persistence of the shocks is very similar to the persistence of the deviations from the federal funds rate from target observed in the data and reported in equation (1). This similarity lends further support to the model.

\section{Graphical IIlustration}

Figure 7 provides a graphical illustration of the supply and demand model and illustrates the simulations of an increase in the target federal funds rate discussed above. The announcement causes the demand curve to shift because the fund rate is expected to rise. Thus the initial impact is an increase in the funds rate with no change in supply. Eventually supply does move as the Trading Desk follows the reaction function.

\section{CONCLUSION}

The simple model of the supply and demand for Fed balances presented in this paper is capable of explaining the "open mouth operation" phenomenon: Changes in the target federal funds rate cause changes in the actual federal funds rate with little or no immediate action by the Trading Desk. However, traditional "open market operations" are

\footnotetext{
${ }^{15}$ See Poole and Rasche (2000).
} 


\section{Figure 6}

\section{Response of the Federal Funds Rate to a Shock to the Demand for Reserve Balances on Day 1}

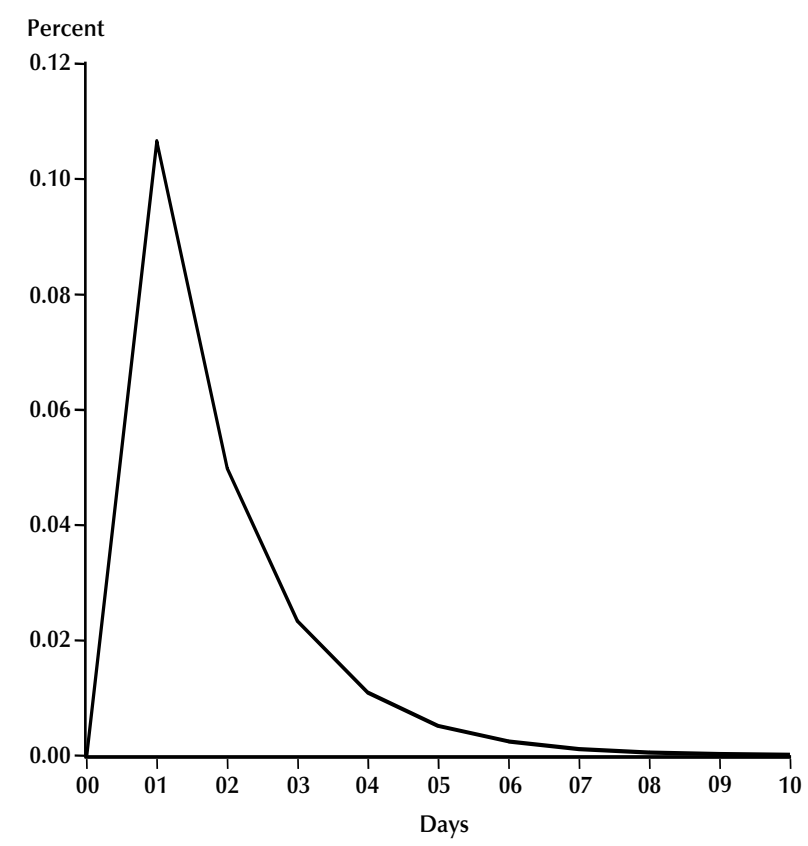

the fundamentals that underlie these announcement or expectations effects. By specifying a reaction function of the Trading Desk and showing how the demand for Fed balances depends on expectations of the future federal funds rate, the model demonstrates how it is the "threat" of future open market operations that actually moves the rate. One reason why, at the times of target rate changes, the deviations of the federal funds rate from the target rate have diminished may be that traders are placing increased credibility on the reaction function of the Trading Desk as the FOMC has provided greater clarity about the target itself. ${ }^{16}$

The same model also seems capable of explaining the time series properties of the deviations of the federal funds rate from target. Future research should be aimed at getting more precise functional forms and parameter values so that the model can be used to investigate other policy issues, including the reduced volatility and increased persistence of

\footnotetext{
16 Three of the four cases where volatility of the deviations was high in this sample were associated with the easing at the time of the Russian and Long Term Capital Management crises. Thus, an alternative explanation for the decline in volatility is that traders found those changes to be more of a surprise.
}

\section{Figure 7}

\section{Graphical Illustration of an "Open Mouth" Effect}

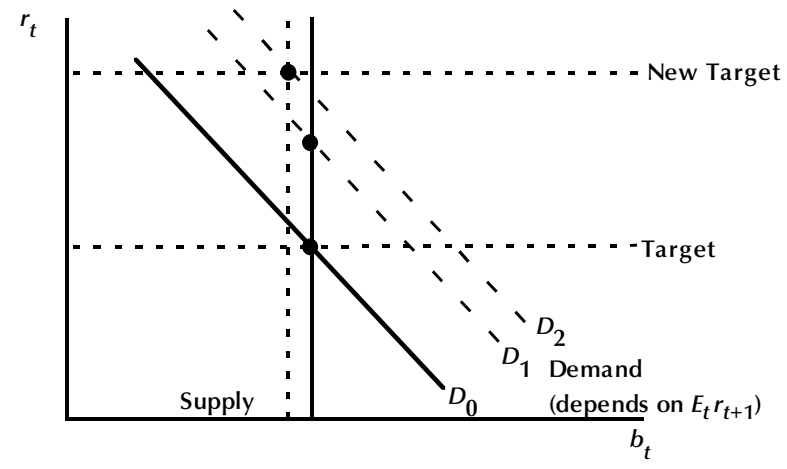

NOTE: This Figure corresponds with Figure 5. When the target rate increase is announced the demand curve shifts from $D_{0}$ to $D_{1}$ and without any changes in supply the funds rate $r_{t}$ rises. In later periods the supply is reduced and the demand curve shifts up a little more.

funds rate deviations from target in recent years demonstrated in the paper. Time series data on prices on individual federal funds transactions will aid this estimation.

It is also important to examine how this type of model works in overnight markets in other countries. Blenck (2000) provides a useful comparison of how the Bank of Japan, the European Central Bank, and the Federal Reserve System intervene in the overnight markets. And the use of regular lending and borrowing facilities is becoming more common, with the Reserve Bank of New Zealand and the Bank of Canada being two prominent examples. The similarities and differences between these financial markets and the central bank operations will provide a useful perspective on the kind of model presented here.

\section{REFERENCES}

Blenck, Denis. "The Main Features of the Monetary Policy Frameworks of the Bank of Japan, the Federal Reserve System, and the Eurosystem." Unpublished manuscript, European Central Bank, 2000.

Fisher, Peter. "Domestic Open Market Operations During 1999." Federal Reserve Bank of New York, Markets Group, February 2000.

Furfine, Craig H. "The Microstructure of the Federal Funds 
Market." Financial Markets, Institutions and Instruments. November 1999, 8(5), pp. 24-44.

"The Price of Bank Lending and Borrowing: Evidence from the Federal Funds Market.” Bank for International Settlements, 1999.

"Interbank Payments and the Daily Federal Funds Rate." Journal of Monetary Economics, October 2000a, 46(2), pp. 535-53.

"The Reluctance to Borrow from the Fed." Bank for International Settlements, June 2000b.

Meulendyke, Anne-Marie. U.S. Monetary Policy and Financial Markets. Federal Reserve Bank of New York, 1998.

Federal Reserve Board. "Modifications to the FOMC's Disclosure Procedures.” 19 January 2000.

Gilbert, R. Alton. "Operating Procedures for Conducting Monetary Policy.” Federal Reserve Bank of St. Louis Review, January/February1985, 67(2), pp. 13-21.

Guthrie, Graeme and Wright, Julian. "Open Mouth Operations." Journal of Monetary Economics, October 2000, 46(2), pp. 489-516.

Hamilton, James. "The Daily Market in Federal Funds." Journal of Political Economy, February 1996, 104(1), pp. 26-56.

Poole, William and Rasche, Robert. "Perfecting the Market's Knowledge of Monetary Policy.” Journal of Financial Services Research, December 2000, 18(2/3), pp. 255-98.

Rudebusch, Glenn D. "Federal Reserve Interest Rate Targeting, Rational Expectations, and the Term Structure." Journal of Monetary Economics, April 1995, 35(2), pp. 245-74.

Thornton, Daniel L. “The Relationship Between the Federal Funds Rate and the Fed's Federal Funds Rate Target: Is It Open Market or Open Mouth Operations?" Working Paper No. 99-022B, Federal Reserve Bank of St. Louis, December 2000.

Woodford, Michael. "Monetary Policy in a World Without Money." Unpublished paper, Princeton University, 2000. 
RE VIE W

48 July/AUgust 2001 